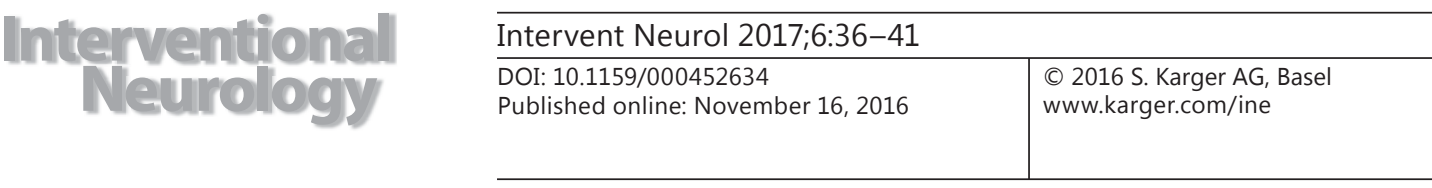

\title{
Comparison of 3-Month Stroke Disability and Quality of Life across Modified Rankin Scale Categories
}

\author{
Srikant Rangaraju Diogo Haussen Raul G. Nogueira Fadi Nahab \\ Michael Frankel \\ Emory University and Grady Memorial Hospital, Atlanta, GA, USA
}

\section{Keywords}

Ischemic stroke · Functional recovery · Cerebrovascular disease · Quality of life · Outcome

\begin{abstract}
Background and Purpose: Modified Rankin Scale (mRS) score 0-2 has been used to define "good outcome" while stroke patients with mRS 3 are grouped with mRS 4-6 as having "poor outcome." Long-term data comparing quality of life (QoL), particularly across the mRS 2, 3, and 4 subgroups, are sparse. Methods: Participants in the Interventional Management of Stroke 3 (IMS3) trial with documented 3-month mRS, functional disability (Barthel index [BI]), and self-reported EQ5D-3L QoL questionnaires at 3 months after stroke were included. EQ5D$3 \mathrm{~L}$ summary indices were calculated using published utility weights for the US population. BI and EQ5D-3L indices were compared across mRS categories using multiple pairwise comparisons with appropriate alpha error corrections. Results: Four hundred twenty-three patients were included (mean age $64 \pm 13$ years, median baseline NIHSS 16 [IQR 12-19], mean BI 84.1 \pm 25.3 , and mean EQ5D-3L index $0.73 \pm 0.24$ ). While significant differences in BI were observed across mRS categories, QoL in the mRS 2 and 3 categories was similar. Based on BI and EQ5D$3 \mathrm{~L}$ index, mRS 3 status was more similar to mRS 2 than to mRS 4 status, and large heterogeneity in the mRS 3 group was observed. Conclusions: Ischemic stroke patients who achieve mRS 2 and 3 functional outcomes seem to have similar health-related QoL scores. mRS $0-3$, rather than $0-2$, should be considered a good outcome category in moderate to severe ischemic stroke.

(c) 2016 S. Karger AG, Basel
\end{abstract}




\section{Introduction}

Disability following ischemic stroke is frequently measured using the modified Rankin Scale (mRS), where 0 represents no disability and 6 represents death [1]. Since the mRS is a nonlinear scale, dichotomization of outcomes has been performed in research studies. In recent stroke trials, 3-month mRS 0-2 was considered "good outcome", while mRS 3-6 was considered "poor outcome" [2]. In current practice, patients with a mRS of 3 are also not typically considered ideal candidates for aggressive stroke treatments [2]. Grouping mRS 3 patients with mRS 4-6 ones assumes that mRS 3 patients are more similar to mRS 4 rather than mRS 2 patients with respect to clinical outcomes, although recent data suggest that 7-year survival is similar for patients with 3-month mRS 2 and 3 outcomes [3]. The highest interrater disagreement has been reported when assigning patients to mRS 2 and 3 categories, raising concerns regarding the validity of this dichotomization [4].

The study of health-related quality of life (QoL), in addition to functional disability resulting from stroke, is critical, since the ultimate goal of any stroke treatment is to preserve and improve long-term QoL. We also currently do not know how different mRS categories are with respect to QoL in the long run. The EQ5D-3L is a 15-item self-reported simple, generic measure of health-related QoL with well-established psychometric properties in the European and US populations and is a frequently used general health status questionnaire in stroke patients [5-7]. The goal of this analysis of the Interventional Management of Stroke 3 (IMS3) trial was to compare outcomes at 3 months after stroke using the Barthel index (BI) and health-related QoL (EQ5D-3L summary index), across the mRS 0-5 categories.

\section{Methods}

Study Population and Ethical Considerations

The IMS3 trial was an NIH-funded multicenter, 2-arm study evaluating clinical outcomes after intravenous tPA alone versus intravenous tPA with endovascular therapy in patients with acute ischemic stroke, and the results were previously published [8]. The study included subjects aged 18-82 years, with initiation of intravenous tPA within $3 \mathrm{~h}$ of onset of stroke symptoms and moderate to severe stroke severity (NIHSS $\geq 10$ or $\geq 8$ points) with confirmed large vessel occlusion at the onset of intravenous tPA. IMS3 participants who had a documented 3-month mRS, BI, and self-reported EQ5D-3L questionnaire were included. Our analysis was a secondary analysis of the deidentified IMS3 dataset that has been made publicly available by the $\mathrm{NIH}$, and permission to use this dataset was obtained. Our study was deemed exempt from local institutional review board review as it was not considered human subjects research due to complete deidentification of the dataset.

\section{Study Measures}

BI, mRS, and EQ5D-3L were collected prospectively in IMS3. Three-month mRS and BI were determined by blinded study investigators not involved in acute management. Using published utility weights for a US population, an EQ5D-3L summary index score was calculated for each participant [5, 7, 9]. For the US general population, the possible EQ5D-3L index scores range from -0.11 to $1.0,0.0$ representing death and 1.0 perfect health. Patients who died prior to 3 months were excluded and no imputation was performed.

Statistical Analysis

Median BI and EQ5D-3L summary indices were calculated for the mRS 0-5 categories. Pairwise comparisons ( $m R S 1$ vs. 2, 2 vs. 3, 3 vs. 4, and 4 vs. 5) were performed using the Mann-Whitney U test with Bonferroni correction ( $p<0.0125$ was considered significant). Median BI and EQ5D-3L summary indices were plotted on a scatter diagram to visualize the similarities between the mRS 0-5 categories. 


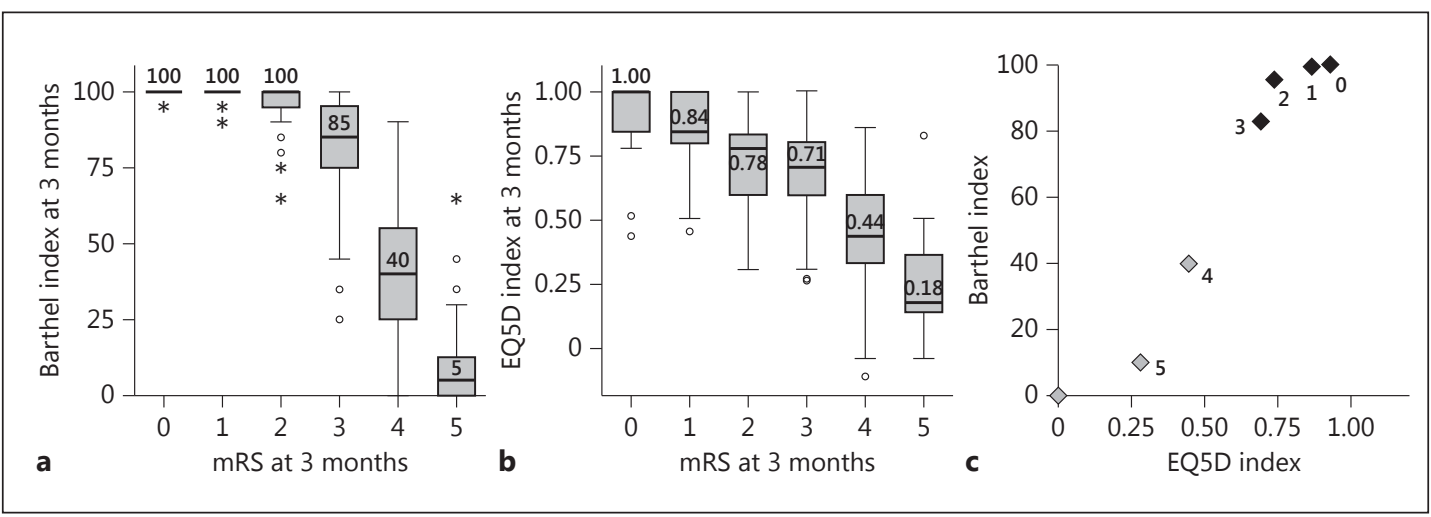

Fig. 1. Comparison of Barthel index and quality of life across the modified Rankin Scale categories. Circles represent mild outliers (beyond 1.5× IQR), asterisks represent extreme outliers (beyond 3× IQR).

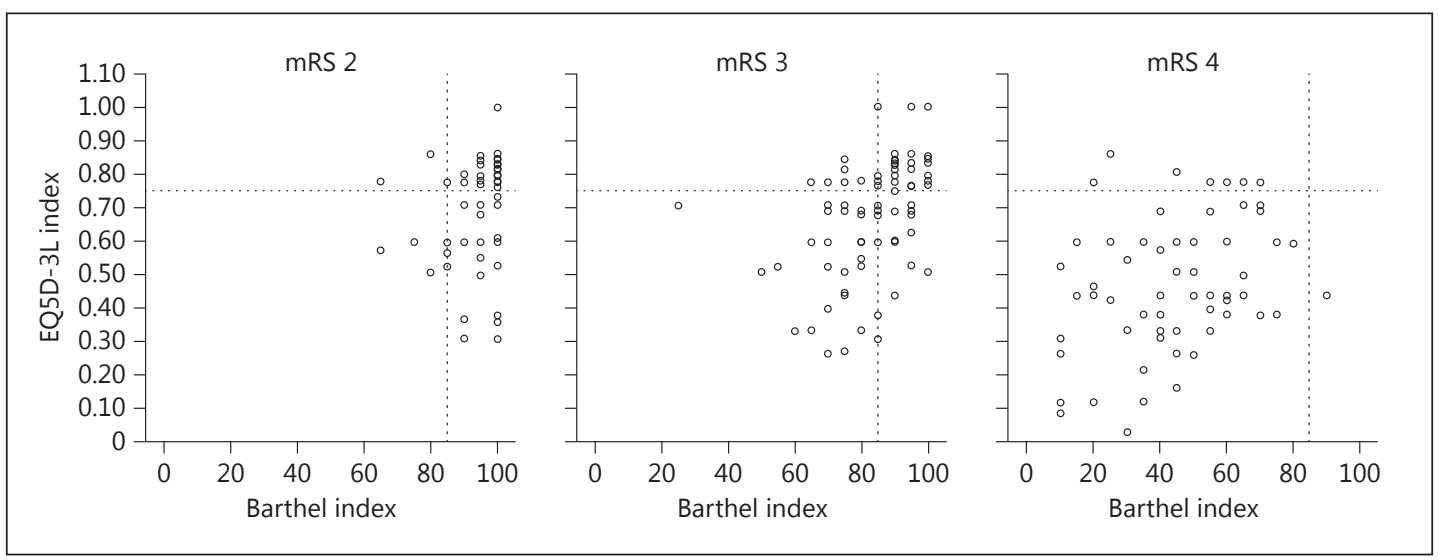

Fig. 2. Heterogeneity in Barthel index and quality of life in the modified Rankin Scale 2-4 categories.

\section{Results}

\section{Patient Characteristics}

Of 656 IMS3 participants, 423 had all 3 outcome variables at 3 months. The mean age was $64(\mathrm{SD}=13)$ years, median admission NIHSS was 16 (IQR 12-19), and 60.3\% (255/423) achieved mRS 0-2 at 3 months. Median BI was 100 (IQR 75-100) and mean EQ5D-3L summary index was $0.727(S D=0.24)$. As a reference, the mean EQ5D-3L index for the general US adult population is 0.86 , while that for individuals aged $65-74$ is 0.78 [10].

\section{Comparison of Disability and QoL Levels and Their Variability across $m R S$ Categories}

Significant overall differences in BI and QoL were observed across 3-month mRS categories (Kruskal-Wallis ANOVA $p<0.001$ for each). Pairwise nonparametric tests were used due to negatively skewed distributions of both metrics (skewness statistics $\leq-1.0$ ). In pairwise comparisons, significant differences in BI were observed between mRS 1 versus 2, 2 versus 3 , and 3 versus 4 categories (Fig. 1a). However, significant differences in QoL were only found between mRS 1 versus 2 and mRS 3 versus 4, but not for mRS 2 versus 3 comparisons (Fig. 1b). Based on BI and QoL, mRS 3 patients were more similar to mRS 2 rather than mRS 4 patients (Fig. 1c). The mRS 3 and 4 groups were far more heterogeneous than the mRS 2 group (Fig. 2). 


\section{Discussion}

We have shown that health-related QoL in patients with mRS 2 and 3 outcomes are similar, despite differences in functional disability. Patients who achieve mRS 3 more closely resemble mRS 2 than mRS 4 patients based on functional disability and QoL. Our results also agree with a prior disability-weighted analysis of the mRS in suggesting that mRS 2 and 3 outcomes may be similar [11]. While the mRS 2 category is relatively homogenous with respect to $\mathrm{BI}$, we observed greater heterogeneity in the mRS 3 category. This may be explained by lower interrater reliability in classifying patients as mRS 2 and 3 or by the existence of subgroups within the mRS 3 group [4]. These possibilities need to be clarified in future research studies.

An analysis of a Polish inpatient stroke population (median 8 days post stroke) found that patients with mRS 3 had lower EQ5D-3L indices (mean $=0.597$ ) than mRS 2 patients (mean $=0.705$ ), while the overall mean QoL index was 0.59 [6]. In contrast our study, using long-term QoL data from IMS3, found no difference in mRS 2 and 3 categories, while the overall mean EQ5D-3L index (0.727) was much higher. Since IMS3 assessed QoL 3 months post stroke, allowing recovery and adjustment to stroke disabilities, our results are more reflective of the long-term impact of poststroke disabilities on QoL.

Our findings are also important in light of the recent demonstration of efficacy of endovascular therapy in patients with large vessel occlusions. Since patients with mild to moderate prestroke disabilities (mRS 2-3) were excluded (exclusion criteria: $\mathrm{BI}<90$ or mRS $>1$ ) from these studies, the AHA/ASA guidelines state that endovascular therapy may be considered for patients with prestroke $\mathrm{mRS}>1$ (class $2 \mathrm{~B}$, level of evidence B-R) and that further randomized studies are warranted [2]. In current practice, patients with a baseline mRS of 3 are typically excluded from endovascular therapy, while mRS 2 patients are more frequently offered this treatment. Our results suggest that some patients labelled as mRS 3, who have a BI and QoL that resemble those of mRS 2 patients, may be considered suitable candidates for endovascular stroke therapy.

The nonlinearity of the mRS is a limitation of this outcome scale, and dichotomization of the mRS can potentially limit the power of statistical analyses. Therefore, the development and increasing use of ordinal mRS "shift" analysis and weighted mRS schema represent significant advances in the stroke research field [11-14]. As shown recently, utility-weighted mRS performed similarly to ordinal mRS in detecting treatment effects in published stroke trials and outperformed dichotomous mRS-based analyses [12]. However, the interpretation of effect size using the ordinal mRS shift analysis, as well as application of results using these approaches to an individual patient, can be quite challenging. In a meta-analysis of recently published positive endovascular stroke trials, both ordinal mRS shift as well as dichotomized mRS approaches yielded very similar statistically significant results [14]. Published utility values of mRS categories were 1.0 for mRS level 0, 0.91 for mRS level 1, 0.76 for mRS level 2, 0.65 for mRS level 3, 0.33 for mRS level 4, and 0 for mRS level 5-6; this also corroborates our findings that mRS 3 is much more similar to mRS 2 than to mRS 4. Since clinical practice still employs mRS 2 and 3 cutpoints as measures of functional independence and dichotomization of mRS is likely to be used in future research studies, our results are potentially useful in clinical practice and research, despite the limitations of mRS dichotomization and the advances in clinical research methods.

A limitation of this study is that EQ5D-3L was the only QoL metric used. Newer and more elaborate QoL questionnaires have been validated for stroke, and further research is needed to validate our observations using these measures $[15,16]$. 


\section{Conclusions}

QoL is similar in the mRS 2 and 3 categories despite differences in functional disability, supporting the use of mRS 0-3 rather than mRS 0-2 as a measure of long-term good outcome in moderate to severe ischemic stroke patients.

\section{Acknowledgments}

Dr. Rangaraju was supported by the American Brain Foundation and by the National Center for Advancing Translational Sciences of the National Institutes of Health under award number ULITR000454.

\section{Disclosure Statement}

Dr. Nogueira: PI Trevo-2 Trial (modest), DAWN trial PI (no compensation), Steering Committees of SWIFT (modest), and SWIFT Prime (no compensation) trials; received compensation from the STAR Trial (Angiographic Core Lab-significant), is part of the Executive Committee for Penumbra-3D Trial (no compensation), and is Editor-in-Chief of Interventional Neurology (no compensation). The other authors have nothing to disclose.

\section{References}

1 van Swieten JC, Koudstaal PJ, Visser MC, Schouten HJ, van Gijn J: Interobserver agreement for the assessment of handicap in stroke patients. Stroke 1988;19:604-607.

2 Powers WJ, Derdeyn CP, Biller J, Coffey CS, Hoh BL, Jauch EC, Johnston KC, Johnston SC, Khalessi AA, Kidwell CS, Meschia JF, Ovbiagele B, Yavagal DR; American Heart Association Stroke Council: 2015 American Heart Association/American Stroke Association focused update of the 2013 guidelines for the early management of patients with acute ischemic stroke regarding endovascular treatment: a guideline for healthcare professionals from the American Heart Association/American Stroke Association. Stroke 2015;46:3020-3035.

3 Magalhaes R, Abreu P, Correia M, Whiteley W, Silva MC, Sandercock P: Functional status three months after the first ischemic stroke is associated with long-term outcome: data from a community-based cohort. Cerebrovasc Dis 2014;38:46-54.

4 Wilson JT, Hareendran A, Hendry A, Potter J, Bone I, Muir KW: Reliability of the modified Rankin Scale across multiple raters: benefits of a structured interview. Stroke 2005;36:777-781.

5 Johnson JA, Coons SJ, Ergo A, Szava-Kovats G: Valuation of EuroQOL (EQ-5D) health states in an adult US sample. Pharmacoeconomics 1998;13:421-433.

6 Golicki D, Niewada M, Buczek J, Karlinska A, Kobayashi A, Janssen MF, Pickard AS: Validity of EQ-5D-5L in stroke. Qual Life Res 2015;24:845-850.

7 Shaw JW, Johnson JA, Coons SJ: US valuation of the EQ-5D health states: development and testing of the D1 valuation model. Med Care 2005;43:203-220.

8 Broderick JP, Palesch YY, Demchuk AM, Yeatts SD, Khatri P, Hill MD, Jauch EC, Jovin TG, Yan B, Silver FL, von Kummer R, Molina CA, Demaerschalk BM, Budzik R, Clark WM, Zaidat OO, Malisch TW, Goyal M, Schonewille WJ, Mazighi M, Engelter ST, Anderson C, Spilker J, Carrozzella J, Ryckborst KJ, Janis LS, Martin RH, Foster LD, Tomsick TA; Interventional Management of Stroke (IMS) III Investigators: Endovascular therapy after intravenous t-PA versus t-PA alone for stroke. N Engl J Med 2013;368:893-903.

9 Johnson JA, Luo N, Shaw JW, Kind P, Coons SJ: Valuations of EQ-5D health states: are the United States and United Kingdom different? Med Care 2005;43:221-228.

10 Luo N, Johnson JA, Shaw JW, Feeny D, Coons SJ: Self-reported health status of the general adult U.S. population as assessed by the EQ-5D and health utilities index. Med Care 2005;43:1078-1086.

11 Hong KS, Saver JL: Quantifying the value of stroke disability outcomes: WHO global burden of disease project disability weights for each level of the modified Rankin Scale. Stroke 2009;40:3828-3833.

12 Chaisinanunkul N, Adeoye O, Lewis RJ, Grotta JC, Broderick J, Jovin TG, Nogueira RG, Elm JJ, Graves T, Berry S, Lees KR, Barreto AD, Saver JL; DAWN Trial and MOST Trial Steering Committees; additional contributors from DAWN Trial Steering Committee: Adopting a patient-centered approach to primary outcome analysis of acute stroke trials using a utility-weighted modified Rankin Scale. Stroke 2015;46:2238-2243. 
13 Goyal M, Demchuk AM, Menon BK, Eesa M, Rempel JL, Thornton J, Roy D, Jovin TG, Willinsky RA, Sapkota BL, Dowlatshahi D, Frei DF, Kamal NR, Montanera WJ, Poppe AY, Ryckborst KJ, Silver FL, Shuaib A, Tampieri D, Williams D, Bang OY, Baxter BW, Burns PA, Choe H, Heo JH, Holmstedt CA, Jankowitz B, Kelly M, Linares G, Mandzia JL, Shankar J, Sohn SI, Swartz RH, Barber PA, Coutts SB, Smith EE, Morrish WF, Weill A, Subramaniam S, Mitha AP, Wong JH, Lowerison MW, Sajobi TT, Hill MD; ESCAPE Trial Investigators: Randomized assessment of rapid endovascular treatment of ischemic stroke. N Engl J Med 2015;372:1019-1030.

14 Saver JL, Goyal M, van der Lugt A, Menon BK, Majoie CB, Dippel DW, Campbell BC, Nogueira RG, Demchuk AM, Tomasello A, Cardona P, Devlin TG, Frei DF, du Mesnil de Rochemont R, Berkhemer OA, Jovin TG, Siddiqui AH, van Zwam WH, Davis SM, Castano C, Sapkota BL, Fransen PS, Molina C, van Oostenbrugge RJ, Chamorro A, Lingsma H, Silver FL, Donnan GA, Shuaib A, Brown S, Stouch B, Mitchell PJ, Davalos A, Roos YB, Hill MD; HERMES Collaborators: Time to treatment with endovascular thrombectomy and outcomes from ischemic stroke: a meta-analysis. JAMA 2016;316:1279-1288.

15 Kozlowski AJ, Singh R, Victorson D, Miskovic A, Lai JS, Harvey RL, Cella D, Heinemann AW: Agreement between responses from community-dwelling persons with stroke and their proxies on the NIH neurological quality of life (Neuro-QoL) short forms. Arch Phys Med Rehabil 2015;96:1986-1992.e14.

16 Lin KC, Fu T, Wu CY, Hsieh YW, Chen CL, Lee PC: Psychometric comparisons of the Stroke Impact Scale 3.0 and Stroke-Specific Quality of Life Scale. Qual Life Res 2010;19:435-443. 